\title{
Giant Axonal Neuropathy: Visual and Oculomotor Deficits
}

\author{
T.H. KIRKHAM, D. GUITTON and S.G. COUPLAND
}

SUMMARY: Giant axonal neuropathy, a generalised disorder or neurofilaments, presents as a chronic, progressive peripheral neuropathy in childhood. Evidence for central nervous system involvement is demonstrated in this study of four male patients with giant axonal neuropathy who had defective visual function and abnormal ocular motility. The visual system was studied by electroretinography, which showed normal retinal function, and by visual evoked potentials, which showed

RESUME: La neuropathie généralisée à axones géants se manifeste chez les enfants comme une neuropathie périphérique à progression lente; les axones contiennent de nombreux microfilaments. Nous présentons quatre patients de sexe masculin qui manifestaient avec évidence une atteinte du système nerveux central par une faiblesse de la vision et par des anomalies de la motricité oculaire. L'électrorétinographie nous a montré un fonctionnement normal de la rétine, tandis que les potentiels évoqués visuels ont démontré des troubles à la fois des nerfs optiques et disease of both optic nerves and retrochiasmal visual pathways. The ocular motility disorder, studied by electrooculography, comprised defective pursuit, inability to maintain eccentric gaze with gaze paretic and rebound nystagmus, abnormal optokinetic responses and failure of suppression of the vestibulo-ocular reflex by fixation. These findings suggested involvement by giant axonal neuropathy of the cerebellar and brain stem pathways important in the control of ocular motility.

dans les voies visuelles rétrochiasmatiques. L'éleciro-oculographie confirma la présence de la poursuite saccadique, l'impossibilité de maintenir le regard eccentrique avec nystagmus paretique du regard et nystagmus de rebond avec le retour à la position primaire. Le nystagmus optocinétique était défectueux et il était impossible de supprimer le réflexe vestibulo-oculaire avec la fixation. Ces signes indiquent globalement une atteinte par la maladie des voies oculomotrices dans le cervelet et du tronc cérébral.

\section{INTRODUCTION}

Giant axonal neuropathy is a chronic, slowly progressive, peripheral neuropathy of childhood; reports of 12 cases have been published. (Asbury et al, 1972; Berg et al, 1972; Carpenter et al, 1973, 1974; Ouvrier et al, 1974; Prineas et al, 1976; Igisu et al, 1975; Koch et al, 1977; Boltshauser et al, 1977; Peiffer et al, 1977; Jedrzejowska and Drac, 1977; Gambarelli et al, 1977; Watters et al, 1978; Mizuno et al, 1979; Larbrisseau et al, 1979; Jones et al, 1979). Development is usually normal until age 18 months to 3 years when progressive gait difficulty and weakness begin. All but two patients (Boltshauser et al, 1977; Jedrzejowska and Drac, 1977) had tightly curled hair. Parental consanguinity was present in three cases (Ouvrier et al, 1974; Prineas et al, 1976; Igisu et al, 1975; Gambarelli et al, 1977) although there were 12 normal siblings in those families. Two siblings reported with the disease makes autosomal recessive inheritance most likely (Jones et al, 1979). The disease has been described in dogs (Duncan and Griffiths, 1977, 1979) where its recessive nature is firmly established (Duncan et al, 1979). Giant axonal neuropathy derives its name from the characteristic sural nerve biopsy which shows numerous swollen axons distended by an increased number of neurofilaments in both motor and sensory nerve fibers. The cytoplasmic microfilaments may also be found in Schwann cells, endothelial cells and skin fibroblasts and the disease is best considered a generalized disorder of cytoplasmic microfilaments (Koch et al, 1977). It is increasingly evident that central nervous system involvement occurs in giant axonal neuropathy. Autopsy showed axonal swelling in the pons and cortex of one case (Peiffer et al, 1977) and extensive 
demyelination and Rosenthal fibers in another (Jones et al, 1979). Central nervous system involvement occurs in dogs. (Griffiths and Duncan, 1979).

We report a neuro-ophthalmic investigation of four boys with giant axonal neuropathy which confirms central nervous system involvement and describe new developments in these previously reported cases (Carpenter et al, 1973, 1974; Watters et al, 1978; Larbrisseau et al, 1979). All had oculomotor abnormalities, documented by electrooculography, and abnormal visual function confirmed by electroretinography and cortical visual evoked potentials.

\section{CASE REPORTS}

Case 1 . He walked unaided at 1 year of age but developed progressive ataxia and weakness by age 2 . At 8 years, visual acuity was right eye 20/80, J 5 and left eye 20/40, $\mathrm{J} \mathrm{l}$, and color vision was absent (Ishihara test). Both fundi showed optic atrophy. Corneae and lenses were normal. Pursuit was jerky in all directions with marked gaze paretic nystagmus horizontally. Prominent rebound nystagmus lasting 10-15 seconds was seen on return to the midline after horizontal eccentric gaze had been maintained for 30 seconds. (fig. 1) Up beat nystagmus occurred on up gaze and a little down beat nystagmus on down gaze. He had failure of fixation suppression of his vestibuloocular reflex (Zee, 1977). Optokinetic responses to the clinical rotating drum were poor. Saccades appeared of normal velocity and amplitude. At 10 years, visual acuity had fallen to right eye $20 / 200, J 1$ and left eye $20 / 80$, J 3 . He could only walk with support. Respiration was labored with constant inspiratory stridor.

Case 2. Clinical details were reported at age 3 years (Carpenter et al, 1973, 1974). At 9 years he had reduced visual acuity, subnormal colour vision and bilateral optic atrophy. The eyes were straight in all positions of gaze. Pursuit was extremely jerky with prominent gaze paretic nystagmus and rebound nystagmus. Upward and downward pursuit were jerky but with no nystagmus. He showed failure of fixation suppression of his vestibuloocular reflex. Optokinetic responses were symmetrical. Saccades appeared of normal amplitude and velocity. At 11 years visual acuity was right 20/30, J 1 and 12 Ishihara plates and left $20 / 40, \mathrm{~J} 2$ and only 4 Ishihara plates. Up beat nystagmus occurred and optokinetic responses were poor. He could walk unaided with difficulty.
Case 3. This boy was seen at age 19 months because of slow development. He was not walking, was hypotonic, had tight, curly hair and absent reflexes. He walked without support at age 3 years. Examination at 4,5 and 6 years showed normal eye movements but at $61 / 2$ years pursuit became jerky with nystagmus on horizontal and upward gaze. At 9 years he showed slight ptosis and facial diplegia. Speech was poor and he had marked gait difficulty with both proximal and distal weakness in all limbs. Sensation was normal but position sense and deep tendon reflexes were absent. Vision was 20/25, J 1 and 14 colour plates bilaterally and the discs were pale. Optokinetic responses were absent and there was prominent rebound nystagmus. Saccades were normal.

Case 4. This 10 year old boy was reported at the age of 8 when visual function was considered normal and slight restriction of gaze was noted. (Larbrisseau et al, 1979). He walked at 21 months but then steadily deteriorated and was bound to a wheelchair by 8 years. Respiration had been difficult for 2 years with marked inspiratory stridor. Severe dysarthria was present. Corrected visual acuity was $20 / 200$, J 16 and no Ishihara plates with each eye. Bilateral optic atrophy was present. Pursuit was extremely jerky with gaze paretic and rebound nystagmus horizontally and up beat nystagmus on up gaze. No optokinetic responses were obtained. Saccades were normal.

\section{Comment}

All 4 boys had tightly curled hair with slowly progressive peripheral neuropathy worse in the legs than the arms. Gait deterioration, with progressive leg weakness, absent reflexes and muscle wasting, was one of the first problems and later respiratory difficulty and dysarthria were prominent. Cerebrospinal fluid and serum creatine phosphokinase were normal. Electroencephalograms showed mild non specific abnormalities. Computerized axial tomograms were normal. Electromyography and nerve conduction studies were normal during the first three years of life even though clinical deficits were present but by 4 or 5 years these studies showed axonal degenerating neuropathy, more marked in the legs than the arms. Sensory action potentials were absent at this stage. The diagnosis was confirmed by sural nerve biopsy which showed greatly enlarged axons packed with neuro- filaments. (fig. 2) These patients are unrelated, there was no familial consanguinity and no siblings were affected.

None of the children complained of poor visual function, only the parents of Case 1 were aware of a problem, having been informed by the school. Visual evoked potentials and electroretinography (figs. 3, 4, 5) and electrooculography (figs. 1, 6, 7, 8 and tables 1 and 2) were undertaken to supplement and document the clinical neuroophtalmological findings.

\section{METHODS}

\section{Visual Electrophysiology}

Scotopic and photopic electroretinograms (ERG) and cortical visual evoked responses (VER) were recorded. The averaged ERGs were referentially recorded from infraorbital sites (OS and $\mathrm{OD}$ ) using $\mathrm{Ag}-\mathrm{AgCl}$ electrodes secured by adhesive skin collars, while the VERs were recorded from $0_{1}$ and $0_{2}$. Active sites were referred to linked mastoids and interelectrode impedance was maintained below 5,000 ohms. Responses to 256 flashes were amplified by Grass Model P5 amplifiers, band pass filtered $(1-250 \mathrm{~Hz})$, stored on an FM instrumentation tape recorder (Ampex S-300) and simultaneously signal-averaged with a Nicolet Fabritek 1070.

The pupils were dilated and the subjects dark adapted for 15 minutes before scotopic responses were recorded. Scotopic stimulation using a Grass Ps2 photic stimulator flickering at $4.5 \mathrm{~Hz}$ through a Wratten 47B blue filter producing an incremental flicker luminance of $0.86 \mathrm{~cd} / \mathrm{m}^{2}$. The photoflash, positioned $56 \mathrm{~cm}$. from the subject, was masked to provide a 12 degree test-field centered on a 60 degree surround maintained at $0.65 \mathrm{~cd} / \mathrm{m}^{2}$. For photopic recordings the background luminance was maintained at $183 \mathrm{~cd} / \mathrm{m}^{2}$ and the test field flickered at $4.5 \mathrm{~Hz}$ using a red Wratten 25 stimulus of $65 \mathrm{~cd} / \mathrm{m}^{2}$.

\section{Electrooculography}

Horizontal eye movements were recorded using Beckman silver-silver chloride skin electrodes. Rectilinear recordings were made on an ink jet chart recorder after D C amplification. Calibration was made by measuring 

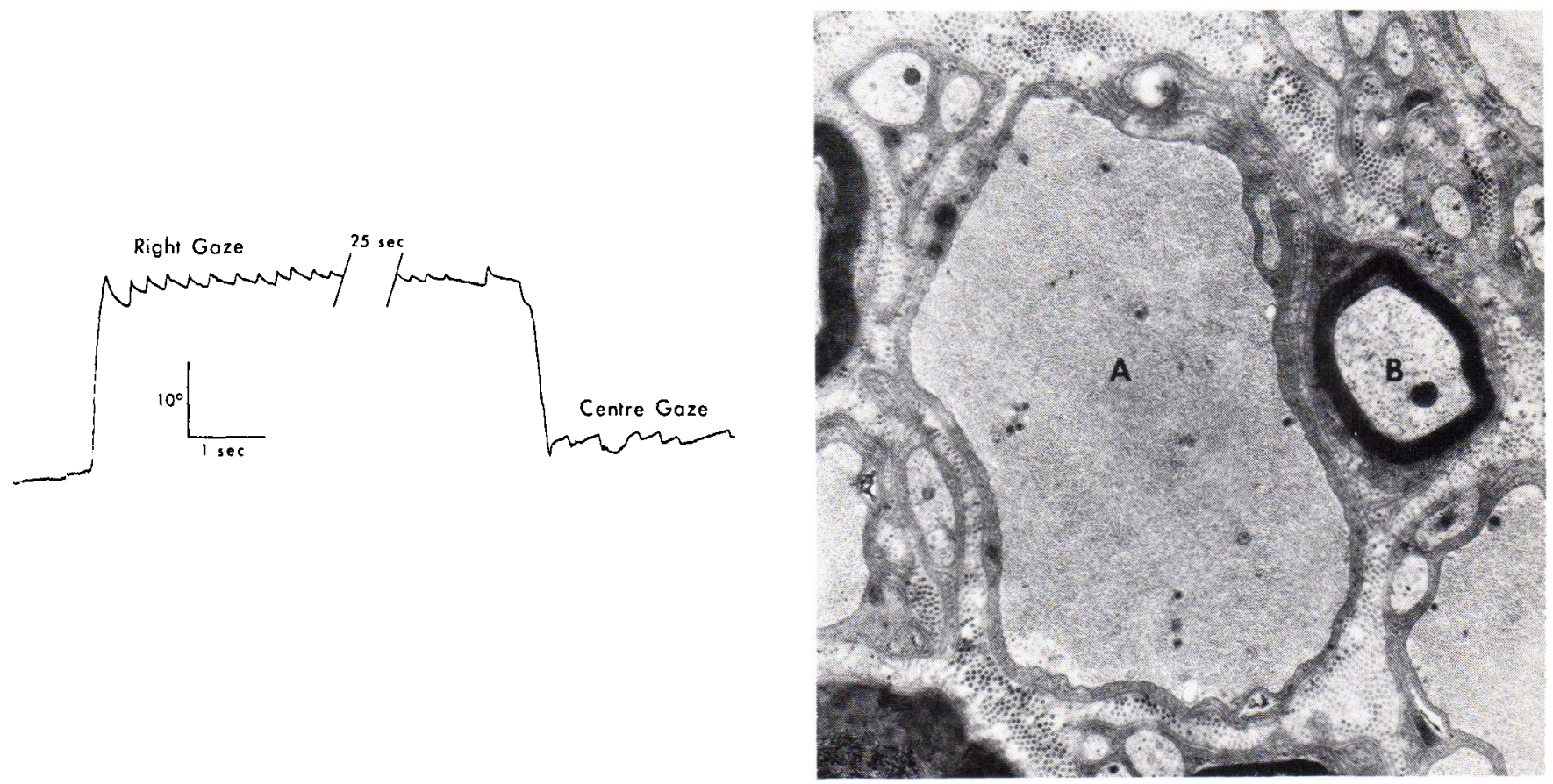

Figure 1 - Electrooculogram shows eyes initially still in mid position. Gaze paretic nystagmus (note exponential slow phase) occurs on right gaze. Rebound nystagmus occurs on return to midline after 30 seconds eccentricity.

Figure 2 - Electron microscopy of sural nerve (original magnification $x 14,000$.) The enlarged axon $(A)$ is clearly too large to be unmyelinated and its cytoplasm is packed with neurofilaments and lacks neurotubules. The smaller myelinated axon (B) is normal. saccades from the midline to targets $25^{\circ}$ right and left. Pursuit was studied using a light spot projected onto a screen $30 \mathrm{~cm}$ from the subjects eyes. The spot subtended an angle of $0.3^{\circ}$ from the eyes and moved back and forth in constant velocity segments i.e. a triangular wave form. Optokinetic stimulation was produced using a projector and the induced nystagmus recorded for different stimulus velocities. The stimulus, projected onto a screen $30 \mathrm{~cm}$ from the eyes, occupied about $110^{\circ}$ of the visual field. Caloric irrigation was given for 20 seconds using water at $30^{\circ} \mathrm{C}$ from a bath with automatic temperature control. The slow phase velocity was measured at the peak of the response with the eyes closed and the ability to visually suppress the post-caloric nystagmus was tested about 100 seconds from the beginning of the irrigation by asking the subject to open the eyes and fixate a target. No patient was taking drugs.

\section{RESULTS}

\section{ERGs and VERs}

The scotopic ERG of case 1 showed b-wave implicit time and peak amplitude within normal limits (fig. 3). The scotopic VERs showed delayed latency of the major negative and positive components over both hemispheres with an interhemispheric asymmetry in wave form (fig. 3). This interhemispheric peak latency difference suggests asymmetrical involvement of the retrochiasmal pathways. The scotopic ERG of case 2 was normal, but there was delay of early negative and later positive components of the VER.

The photopic ERG b-wave peak amplitudes and implicit times were normal for cases 1 and 2. Photopic ERGs were not recorded in the other two patients. Photopic VERs of all four patients showed significantly delayed major negative and positive peak latencies (fig. 4) but with an interhemispheric latency difference as under scotopic conditions. There were also interhemispheric peak latency differences of major negative and positive components detected. under both monocular (fig. 4) and binocular stimulation (fig. 5). In case 2 these findings were associated with absence of the major negative component of the VER (fig. 5).

In summary both photopic and scotopic electroretinal function is well preserved in giant axonal neuropathy but there are severe and asymmetrical conduction deficits along the optic nerves and visual pathways.

\section{OCULAR MOTILITY}

\section{Clinical Findings}

All four patients had grossly jerky pursuit horizontally and vertically. There was marked horizontal gaze paretic nystagmus with rebound nystagmus on return of the eyes to the 


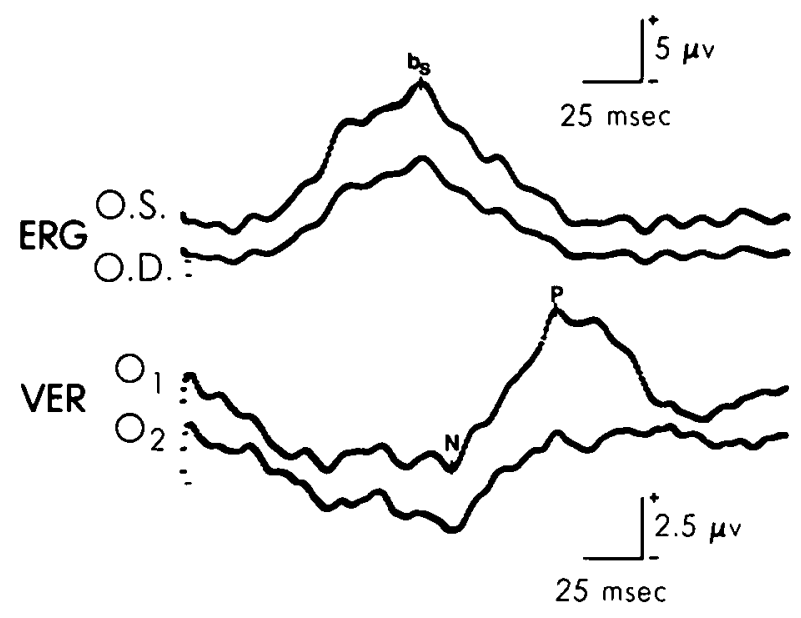

Figure 3 - Averaged scotopic ERG's and VER's of case 1. ERG's from left (OS) and right (OD) eyes show normal b wave amplitude and latency. The VER's show delayed major negative (N) and positive (P) components over left $\left(\mathrm{O}_{1}\right)$ and right $\left(\mathrm{O}_{2}\right)$ occipital sites with smaller amplitude recorded over right side.
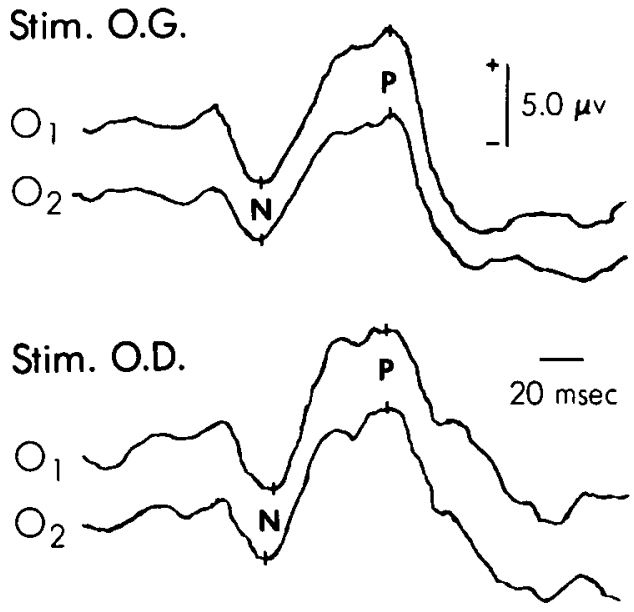

Figure 4 - Averaged photopic VER's from case 4. Delay of major negative $(\mathrm{N})$ and positive $(\mathrm{P})$ components after monocular stimulation of left (OG) and right (OD) eyes. Significant interhemispheric latency difference of major negative $(N)$ component after right eye stimulation. midline. Upbeat and sometimes downbeat nystagmus occurred on up and down gaze respectively. To the clinical optokinetic drum the responses were abnormal, being infrequent and irregular. Saccades appeared normal. The patients were asked to fixate an object rotating at the same velocity as the head. A pointer with a fixation target was held on the patient's head and the head then was rotated from side to side and up and down. Normally the eyes follow the target smoothly but our patients were unable to suppress the vestibuloocular reflex, the eyes being continually carried off the target by the vestibuloocular reflex and repeated saccades were needed to catch the target in both horizontal and vertical planes. The clinical impressions were extended by electrooculography. The deficits were qualitatively similar and only the results of case 1 will be presented in detail. His eye movements were recorded again one year after the original examination to assess any progress in the disease process.

\section{Pursuit System}

There was complete inability to pursue accurately over a velocity range of 3 to $33^{\circ} / \mathrm{sec}$. This was due to two causes: difficulty of maintaining the eyes in an eccentric position (see below) and deficient pursuit per se. This is shown in fig. 6 where the target velocity was about $12^{\circ} / \mathrm{sec}$. With the eyes more than $15^{\circ}$ eccentric from the primary position there was marked tendency to drift from the target back to the midline and pronounced gaze paretic nystagmus is evident. As the target changed direction, the combined pursuit velocity plus eye drift velocity at times exceed the target velocity and small saccades backwards to the target occur. Only as the target crossed the central gaze position was there any semblance of true pursuit in that eye velocity almost matched the target velocity. Even so, catch-up saccades were continually required to keep the eyes on the target. Several traces were measured in the zone where the eye was near the central gaze position to assess the gain of the pursuit system (gain being eye velocity/target velocity). The pursuit velocity saturated at about $10-11^{\circ} / \mathrm{sec}$. and this remained stable over a one year period. (Table 1). For target motion below $10^{\circ} / \mathrm{sec}$. the pursuit system gain was never unity but ranged between 0.73 to 0.83 .

\section{Optokinetic System}

Optokinetic responses were measured at 3 stimulus velocities. The gain (maximum slow phase nystagmus velocity/optokinetic stimulus velocity) was assessed over the first 10 seconds of stimulation excluding the initial responses occurring in the first second. In normal naive control subjects the gain of optokinetic nystagmus reaches its maximum within one second and after about 10 seconds may decrease due to lack of attention to the stimulus. The maximum eye velocity saturated at about $13^{\circ} / \mathrm{sec}$. on the first visit and $21^{\circ} / \mathrm{sec}$. one year later. The gain was poor even at low stimulus velocity. During the second visit, when some improvement was observed, perhaps due to better attention to the stimulus, the maximum gain was 0.68 . (Fig. 7 and table 2).

Attention of all patients to the optokinetic stimulus waned after about 15 seconds of stimulation so that the gain fell rapidly. At 50 seconds they were exhorted to be attentive to the stimuli and at 60 seconds the stimulus was extinguished leaving the patient in total darkness. It was difficult to assess the existence of optokinetic after nystagmus (OKAN) but our impression, following comparison with normal subjects, was that no OKAN was present. 


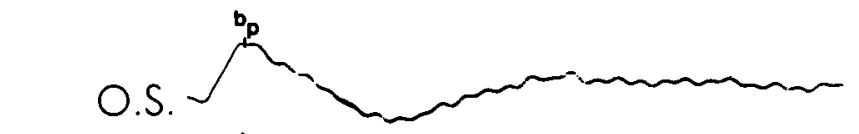

ERG

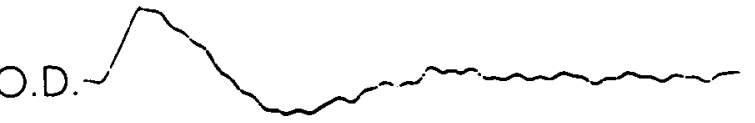

VER

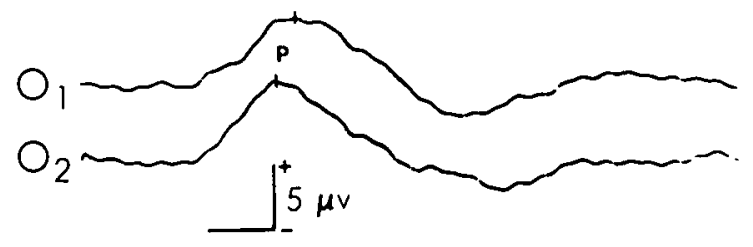

$50 \mathrm{msec}$

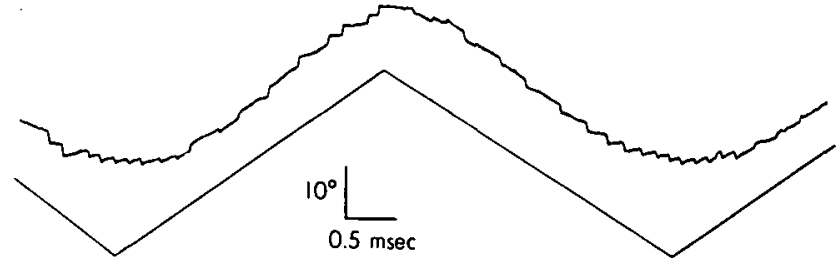

Figure 6 - Typical pursuit tracing shows marked gaze paretic nystagmus as extreme gaze positions are approached and tendency to drift back towards midline. Full description given in text.

TABLE I

Smooth Pursuit Results. Ramp Motion to the Right

\begin{tabular}{lrrrrrr}
\hline \multicolumn{1}{c}{ Measurement } & \multicolumn{2}{c}{ First Visit } & \multicolumn{5}{c}{ One Year Later } \\
\hline Stimulus velocity $\%$ sec. & 6 & 12.2 & 3.3 & 6.5 & 13.1 & 32.7 \\
Mean pursuit velocity & 4.8 & 9.5 & 2.4 & 5.5 & 10.7 & 10.6 \\
at central gaze position $\% /$ sec. & \pm 1.2 & \pm 1.7 & \pm 0.4 & \pm 0.4 & \pm 0.8 & \pm 0.9 \\
Gain of pursuit system & 0.79 & 0.77 & 0.73 & 0.83 & 0.82 & 0.32 \\
\hline
\end{tabular}

TABLE 2

Horizontal Optokinetic Nystagmus. Slow Phase to the Right

\begin{tabular}{lrrrrrr}
\hline \multicolumn{1}{c}{ Measurement } & \multicolumn{3}{c}{ First Visit } & \multicolumn{3}{c}{ One Year Later } \\
\hline Stimulus velocity $\%$ sec. & 24 & 42 & 128 & 28 & 52 & 108 \\
Mean slow phase eye & 8.6 & 9.7 & 12.8 & 21.4 & 21.2 & 21.1 \\
velocity $\%$ sec. & \pm 1.2 & \pm 2.1 & \pm 5.9 & \pm 9.8 & \pm 4.0 & \pm 4.9 \\
Gain of OKN system & 0.35 & 0.23 & 0.10 & 0.08 & 0.41 & 0.19 \\
\hline
\end{tabular}

Gain and mean slow phase eye velocity measured during the time period $1.0 \mathrm{sec} .<K<10.0 \mathrm{sec}$. where $t=0$ corresponds to start of stimulus.

\section{Gaze Paretic and Rebound Nystagmus}

The patients were asked to make a $25^{\circ}$ saccade to an eccentric target horizontally and to maintain fixation upon the target. Gaze paretic nystagmus occurred showing a characteristic decreasing exponential velocity of the slow phase. (Zee et al, 1976). After eccentric gaze was maintained for 30 seconds the eyes were returned by a saccade to the midline (fig. 1).
Prominent rebound nystagmus was seen whose slow phase had a decreasing velocity exponential slope and whose duration was from 8 to 15 seconds.

\section{Vestibular Nystagmus}

The patients opened their eyes and fixated a target when the caloricallyinduced vestibular nystagmus was at its maximum. None could suppress the nystagmus slow phase velocity although perhaps the amplitude was somewhat reduced. (fig. 8)

\section{Saccadic Eye Movements}

Velocities of a number of saccades measured to and from the midline fell within normal limits for our laboratory. Hypermetria was not seen and hypometria was uncommon. Hypometric saccades were corrected by a single small saccade.

\section{DISCUSSION}

Giant axonal neuropathy is a chronic peripheral neuropathy of childhood readily recognisable because of the associated tightly curled hair. It is now clear that central nervous system involvement occurs since nystagmus was observed in half the patients published, one had poor visual acuity but normal fundi and another had optic atrophy. (Table 3) Our study of 4 boys with giant axonal neuropathy confirms central nervous system involvement since they had abnormal vision and ocular motility.

Visual acuity assessment is not often performed by pediatricians or neurologists who tend to place too much emphasis on fundus examination. Determination of optic disc pallor is not a good way to assess optic nerve function. Pallor implies loss of nerve fibers and hence should only be 


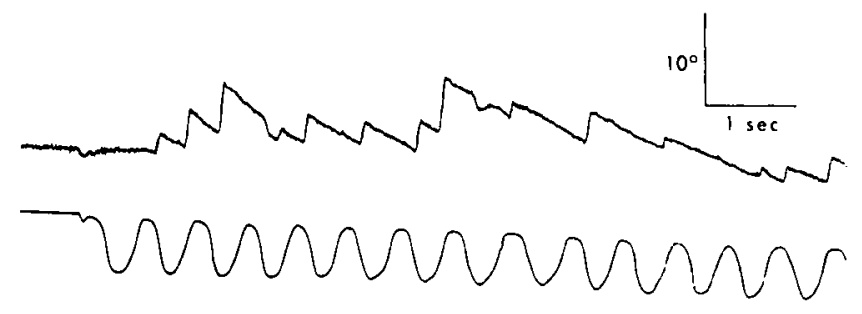

Figure 7 - Initial segment of optokinetic stimulation. Eye movements above and photocell record of stimulus below. Note rapid fall off in slow phase velocity. Full description in text.

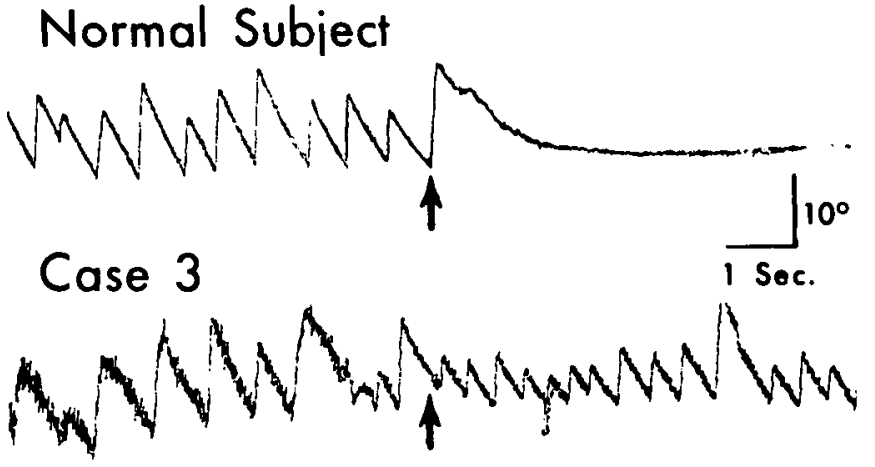

Figure 8 - Post-caloric nystagmus recorded in darkness. Subject opens eyes at arrow and fixates a target. In normal subject nystagmus is inhibited by fixation. In patient, amplitude lessened but slow phase velocity unchanged. inferred to mean atrophy when functional loss can be demonstrated or when defects in the nerve fiber layer of the retina can be seen. (Frisen and Hoyt 1974). Distance and near acuity, colour vision tests, examination of pupillary reactions and visual fields are all possible in children (Kirkham, 1980). Colour vision testing was a particularly reliable indicator of optic nerve dysfunction in our patients, only three of whom had obvious disc atrophy. Electroretinography in 2 patients showed normal retinal function but all 4 had abnormal visual evoked responses (VER) under both scotopic and photopic conditions suggesting marked optic nerve damage (Borda, 1977). Additionally, the VERs of case 2 showed an interhemispheric difference suggesting involvement also of the retrochiasmal visual pathways. Thus, both clinical and electrophysiological evidence shows that giant axonal neuropathy affects the visual system, particularly the anterior visual pathways.

Defective ocular motility mainly affecting the smooth pursuit system became evident around age 6 or 7 years and once developed appeared to remain relatively stable. The patients could not generate eye velocities matching the target velocity so the gain of the pursuit system was always below unity. (Table 1) The pursuit system functions to hold the image of a target on the fovea when the target is moving against a stationary background. The optokinetic system comprises two subsystems respectively driven by a central (foveal) and a peripheral retinal mechanism (Dichgans, 1977) but it is to be recognized that the optokinetic system is not a pursuit system but rather the low frequency supplement of the vestibulo-ocular reflex. It assists in stabilising the eyes during self rotation in a stable visual surround, the only way in which the system is activated in nature. Under our testing conditions where $110^{\circ}$ of the area of the visual field was occupied by the test stimulus both pursuit and peripheral optokinetic systems are activated, the diameter of the stripes used precluding their being considered as merely a foveal stimulus (Dichgans, 1977). This stimulation produces the sensation of circularvection, an illusion of self rotation, which is evidence of true optokinetic stimulation (Robinson, 1977) as well as optokinetic after-nystagmus present in our normal subjects. The maximum slow phase velocity generated by optokinetic stimulation was greater than that for comparable pursuit stimulus velocities (Table 2). Thus, it is possible to distinguish optokinetic from pursuit response and to consider that the peripheral retinal optokinetic system contributed to the response (Robinson, 1977). The optokinetic system gain was low at all stimulus velocities tested and fell off rapidly as stimulus velocity increased. Such abnormal optokinetic responses correlate clinically (Nemet and Ron, 1977) and experimentally (Takemori and Cohen, 1974) with lesions of the cerebellar flocculus and vermis. Normally slow phase velocity increases with increasing stimulus velocity, the linearity of augmentation depending largely on the area of visual field stimulated. Under our testing conditions normal subjects have responses decaying along the curve for a $90^{\circ}$ area of visual field stimulation. (Dichgans, 1977). Raphan, Matsuo and Cohen (1979), believed optokinetic nystagmus was generated by a fast acting pathway to the oculomotor nuclei which immediately drives the eyes at a velocity approaching stimulus velocity, and an indirect pathway, possibly via the vestibular nuclei which involves a velocity storage integrator. This latter "charges" as the stimulus continues and gradually takes over from the fast acting (direct) pathway in maintaining the response. When the stimulus stops the direct pathway is inactivated and optokinetic after nystagmus (OKAN) 
TABLE 3

Previously Published Cases of Giant Axonal Neuropathy

\begin{tabular}{lccc}
\hline \multicolumn{1}{c}{ Reference } & Sex & Vision and Fundi & Ocular Motility \\
\hline Berg et al, 1972; Asbury et al, 1972 & F & Normal fundi and colour vision & mild bilateral ptosis \\
$\begin{array}{l}\text { Carpenter et al, 1973, 1974; } \\
\text { Watters et al, 1978 }\end{array}$ & M & Cranial nerves normal & cranial nerves normal \\
Ouvrier et al, 1974; Prineas et al, 1976 & F & Poor acuity: normal fundi & H and V nystagmus \\
Igisu et al, 1975 & F & Not mentioned & Not mentioned \\
Koch et al, 1977 & M & Not mentioned & Ptosis. H nystagmus \\
Bolthauser et al, 1977; Peiffer et al, 1977 & M & Optic atrophy & Exotropia. H and V nystagmus \\
Jedrzejowska et al, 1977 & M & Fundi normal & cranial nerves normal \\
Gambarelli et al, 1977 & M & Not mentioned & Esotropia. Nystagmus \\
Mizuno et al, 1979 & M & Not mentioned & H and V nystagmus \\
Larbrisseau et al, 1979 & M & Not mentioned & Slightly restricted gaze \\
Jones et al, 1979 & F & Not mentioned & Nystagmus \\
Jones et al, 1979 & F & Not mentioned & Nystagmus \\
\hline
\end{tabular}

The symbols: $\quad M=$ Male $F=$ Female $\quad H=$ Horizontal $V=$ Vertical

continues at a reduced velocity, discharging over its own time course. No OKAN was detected in our patients.

Our patients could not suppress the vestibulo-ocular reflex by fixation clinically which correlates with a defective pursuit system. They also failed to suppress calorically induced nystagmus (fig. 7). Failure of fixation suppression correlates clinically with cerebellar and brain stem disease (Zee et al, 1976; Kirkham et al, 1979). Gaze paretic nystagmus and rebound nystagmus occurred in our patients both showing a decreasing velocity exponential wave form of the slow phase. (fig. 1) The concept of a brain stem integrator (Robinson, 1974) responsible for maintenance of eccentric gaze is well established. This integrator provides a step of innervation to the ocular motor neurones for a given eccentric position and requires cerebellar input to maintain its function. Brain stem or cerebellar disease may result in its dysfunction producing gaze paretic nystagmus. A model of gaze paretic nystagmus shows that it may be present at very small ocular deviations from the mid position depending on the severity of the reduction in the step input of innervation (Abel et al, 1978). Rebound nystagmus may suggest the participa- tion of some attempt at adaptive repair of the faulty integrator (Kirkham et al, 1979). Possibly after prolonged maintenance of eccentric gaze a compensatory bias develops to maintain fixation which slowly decays as the eyes return to the midline resulting in rebound nystagmus. The up beat and down beat nystagmus probably result from damage to the vertical pursuit systems responsible for upward pursuit (Gilman et al, 1977) or downward pursuit (Zee et al, 1974).

Considering the defective pursuit and optokinetic systems and the inability to maintain eccentric gaze, all associated with cerebellar lesions, it is interesting that hypometric saccades, also found in cerebellar disease, were rarely seen. Saccades were generally accurate and none showed evidence of dysfunction of the brain stem saccadic pulse generator (Robinson, 1977). We consider it unlikely that the visual input deficit in our patients contributed to the defects reported in the pursuit, position hold, and optokinetic systems. The gain of the optokinetic system does not depend on central vision (Dichgans, 1977), gaze paretic and rebound nystagmus occur in darkness or behind closed eyelids without benefit of visual input and the patients made accurate saccades to visible targets. The same deficits in the pursuit and optokinetic systems have been described in a number of cerebellar and brain stem diseases where visual function has been normal (Troost and Daroff, 1977; Zee et al, 1976; Kirkham et al, 1979; Kirkham et al, 1980). The oculomotor defects are not obviously specific for giant axonal neuropathy which affects indiscriminantly the pathways responsible for cerebellar and brain stem control of eye movements. The prominence of oculomotor signs from about the age of 6 or 7 years in our patients possibly reflects the ability of nervous system plasticity to delay the onset of signs until the disease is fairly well advanced. Once the signs are present our preliminary clinical and electrooculographic studies suggest that they do not worsen markedly with time.

\section{ACKNOWLEDGEMENTS}

We thank Dr. Stirling Carpenter for the electron micrograph, our colleagues who referred their patients for study, Mr. Marcus Arts and Miss Louise May Blanchet for technical assistance, and Smith Printing Inc Knowlton, and Mr. and Mrs. H. Gratton for financial assistance. 


\section{REFERENCES}

ABEL, L.A., DELL'OSSO, L.F., and DAROFF, R.B. (1978). Analog model for gaze-evoked nystagmus. Trans. Biomed. Eng., 25, 71-75.

ASBURY, A.K., GALE, M.K., COX, S.C., BARINGER, J.R. and BERG, B.O. (1972). Giant axonal neuropathy - a unique case with segmental neurofilamentous masses. Acta Neuropathol., (Berl.) 20, 237-247.

BERG, B.O., ROSENBERG, S.H., ASBURY, A.K. (1972). Giant axonal neuropathy. Pediatrics 49, 894-899.

BOLTSHAUSER, E., BISCHOFF, $A$. and ISLER, W. (1977). Giant axonal neuropathy. Report of a case with normal hair. J. Neurol. Sci., 31, 269-278.

BORDA, R.P. (1977). Visual evoked potentials to flash in the clinical evaluation of the optic pathways. In: Visual evoked potentials in man: new developments. Clarendon Press, Oxford. (DESMEDT, J.E., eds) pp 481-489.

CARPENTER, S., KARPATI, G., ANDERMANN, F. and GOLD, R. (1973). Giant axonal neuropathy: A second case. Neurology (Minn.) 23, 429.

CARPENTER, S., KARPATI, G., ANDERMANN, F. and GOLD, R. (1974). Giant axonal neuropathy. A clinically and morphologically distinct neurological disease. Arch. Neurol. 31, 312-316.

DICHGANS, J. (1977). Optokinetic nystagmus as dependant on the retinal periphery via the vestibular nucleus. In: Control of gaze by brain stem neurons. Developments in Neuroscience. Elsevier/North Holland Biomedical Press. Vol. I (BAKER, R. and BERTHOZ, A., eds) pp 261-266.

DUNCAN, I.D. and GRIFFITHS, 1.R. (1977). Canine giant axonal neuropathy. Vet. Rec. 101, 438-441.

DUNCAN, I.D. and GRIFFITHS, I.R. (1979). Peripheral nervous system in a case of giant axonal neuropathy. Neuropath. App. Neurobiol. 5, 25-39.

DUNCAN, I.D., GRIFFITHS, I.R., HENDERSON, S. and CARMICHAEL, S. (1979). Canine giant axonal neuropathy (GAN) - an inherited disease. Neurology (Minn.) 29, 607.

FRISEN, L. and HOYT, W.F. (1974). Insidious atrophy of retinal fibres in multiple sclerosis. Arch. Ophthal. 92, 91-97.

GAMBARELLI, D., HASSOUN, J., PELLISSIER, J.F., LIVET, M.O., PINSARD, N. and TOGA, M. (1977). Giant axonal neuropathy. Involvement of peripheral nerve, myenteric plexus and extraneuronal area. Arch. Neuropathol. (Berl) 39, 261-269.
GILMAN, N., BALOH, R.W. and TOMIYASU, U. (1977). Primary position upbeat nystagmus. A clinicopathologic study. Neurology (Minn.) 27, 294-298.

GRIFFITHS, I.R. and DUNCAN, I.D. (1979) The central nervous system in canine giant axonal neuropathy. Acta Neuropathol. (Berl) 46, 169-172.

IGISU, H., OHTA, M., TABIRA, T., HOSOKAWA, S., GOTO, I. and KUROIWA, Y. (1975). Giant axonal neuropathy. A clinical entity affecting the central as well as the peripheral nervous system. Neurology (Minn.) 25, 717-721.

JEDRZEJOWSKA, H. and DRAC, H. (1977). Infantile chronic peripheral neuropathy with giant axons. Report of a case. Arch. Neuropathol., (Berl) 37, 213-217.

JONES, M.A., NIGRO, M.A. and BARRE, P.S. (1979). Familial "Giant axonal neuropathy". J. Neuropath., Exp. Neurol. 38, 324.

KIRKHAM, T.H., GUITTON, D., KATSARKAS, A., KLINE, L.B. and ANDERMANN, E. (1979). Oculomotor abnormalities in Friedreich's ataxia. Can. J. Neurol. Sci., 6, 167-172.

KIRKHAM, T.H., COUPLAND, S.G. and GUITTON, D. (1980). Sialidosis: The cherry red spot-myoclonus syndrome. Can. J., Ophthalmol., 7, 35-39.

KIRKHAM, T.H. (1980). Neuro-ophthalmology. In: Paediatric Neurology. Blackwell Scientific Publications. Oxford (Rose, F.C. ed) pp 421-437.

KOCH, T., SCHULTZ, P., WILLIAMS, R. and LAMPERT, P. (1977). Giant axonal neuropathy: a childhood disorder of microfilaments. Ann. Neurol. 1, 438-451.

LARBRISSEAU, A., JASMIN, G., HAUSSER, C., BROCHU, $P$. and GEOFFROY, $E$. (1979). Generalised giant axonal neuropathy. A case with features of Fazio-Londe disease. Neuro-pädiatrie, 10, 76-86.

MIZUNO, Y., OTSUKA, S., TAKANO, Y., SUZUKI, Y., HOSAKA, A., KAGA, M. and SEGAWA, M. (1979). Giant axonal neuropathy. Combined central and peripheral nervous system disease. Arch. Neurol. 36, 107-108.

NEMET, P. and RON, S. (1977). Cerebellar role in smooth pursuit movement. Docum. Ophthalmol. 43, 101-107.

OUVRIER, R.A., PRINEAS, J., WALSH, J.C., REYE, R.D.K. and MCLEOD, J.G. (1974). Giant axonal neuropathy - a third case. Proc. Aust. Assoc. Neurol. II, 137-144.
PEIFFER, J, SCHLOTE, W, BISCHOFF, A BOLTSCHAUSER, E. and MULLER, G. (1977). Generalised giant axonal neuropathy. A filament forming disease of neuronal, endothelial, glial, and Schwann cells in a patient without kinky hair. Acta Neuropathol. (Berl) 40, 213-218.

PRINEAS, J.W., OUVRIER, R.A., WRIGHT, R.G., WALSH, J.C. and MCLEOD, J.G. (1976). Giant axonal neuropathy: A generalised disorder of cytoplasmic microfilament formation. J. Neuropath. Exp. Neurol. 35, 458-470.

RAPHAN, T., MATSUO, V. and COHEN, B. (1979). Velocity storage in the vestibuloocular reflex arc (VOR). Exp. Brain Res. 35, 229-248.

ROBINSON, D.A. (1974). The effects of cerebellectomy on the cat's vestibulo-ocular integrator. Brain Research 71, 195-207.

ROBINSON, D.A. (1974). Vestibular and optokinetic symbiosis: an example of explaining by modelling. In: Control of gaze by brain stem neurones. Developments in neuroscience. Elsevier/North Holland Biomedical Press, Vol. 1. (BAKER, R. and BERTHOZ, A., eds) pp 49-58.

TAKEMORI, S. and COHEN, B. (1974). Loss of visual suppression of vestibular nystagmus after flocculus lesions. Brain Research 72 , 213-224.

TROOST, B.T. and DAROFF, R.B. (1977). The ocular motor defects in progressive supranuclear palsy. Ann. Neurol. 2, 397-403.

WATTERS, G., KARPATI, G., CARPENTER, S., HUMPHREYS, P. and ANDERMANN, F. (1978). Giant axonal neuropathy (GAN). A disorder of the central and peripheral nervous system: clinical, neurophysiological and ultrastructural findings in two patients and review of five previous cases. Canad. J. Neurol. Sci., 5, 340-341.

ZEE, D.S., FRIENDLICH, A.R. and ROBINSON, D.A. (1974). The mechanism of downbeat nystagmus. Arch. Neurol. 30, 227-237.

ZEE, D.S., YEE, R.D., COGAN, D.G., ROBINSON, D.A. and ENGEL, W.K. (1976). Ocular motor abnormalities in hereditary cerebellar ataxia. Brain 99, 207 234.

ZEE, D.S. (1977). Suppression of vestibular nystagmus. Ann. Neurol. 1, 207. 